\title{
Establishment of Slip Coefficient of Slip Resistant Connection
}

\author{
Hwan-Seon Nah, Hyeon-Ju Lee, and Kang-Seok Kim \\ Environmental \& Structural Lab., Korea Electric Power Research Institute, 65 Munji-Ro, \\ Yusung-Gu, Daejon, 305-380, Republic of Korea, e-mail: hsnah@ kepri.re.kr
}

Keywords: Bolt, Slip, Coefficient, Faying Surface, Coating, Torque, Tension

\section{ABSTRCT}

A slip critical joint has various values to adopt the proper slip coefficient in various conditions of faying surfaces in AISC, AIJ and Eurocode 3. The Korean Building Code still regulates the unique slip coefficient, 0.5 , regardless of the diverse faying conditions. In this study, the slip resistance test, including five kinds of surface treatments were conducted to obtain the proper slip coefficients available to steel plate KS SM490A. The faying surfaces were comprised of a clean mill, rust, red lead paint, zinc primer, and shot blast treatment. The candidates for high strength bolts were torque-shear bolts, torqueshear bolts with zinc coating, and ASTM A490 bolts. Based on the test results, the specimens with a shot blasted surface and rusted surface exhibited slip coefficient, 0.61 , and 0.50 , respectively. It is recommended that the slip coefficient of specimens with zinc primer exhibit should be over slip coefficient, 0.42 . The clean mill treated surface had prominently lower values as slip coefficient, 0.27. For red lead painted treatment, the thickness of the coating affects the determinant of slip coefficient, so it is necessary to establish a minimum slip coefficient, 0.21 , with a coating thickness of $65 \mu \mathrm{m}$.

\section{INTRODUCTION}

The bolted connection of steel structure of Nuclear Power Plant structures in Korea was originally designed by high-strength hexagon bolt for slip resistant joints. However, nowadays it is a general tendency that the torque shear type high strength bolt is in place for the high strength hexagon bolt at design of slip resistant joint. The Korean standard for torque shear-type high-strength bolt was initially regulated in 2003. Moreover, the related code ASTM F 2280, as used in the USA, was established in 2006. The torque shear type high strength bolt reaches the required torque when the pin tail twisted off at the end of shank. However this does not mean that even if the pin tail was properly detached from the bolt shank, this bolt has the required direct tension, but only that it was subjected to indirect tension affected by torque. The torque coefficient affects on the 
design strength in tension when it is tightened by the torque control equipment. The tension is in inverse proportion to the torque due to the variation of torque coefficient.

The torque shear type high strength bolts are still dependent on ambient temperature as represented in Korean Standard B2819(2003), which is equivalent to the newly established ASTM F2289(2006). The torque coefficient of high strength bolts responded sensitively to two kinds of factors: ambient temperature and the grip length of the bolt. The pretension for the large diameter of A490 bolt was reported to be dependent on grip length. Recently, the torque-tension relation of high strength bolts was examined from the change of temperature. Subsequently the external load acts in a perpendicular plane to the bolt tension in the slip critical joints. For the last two decades, there have been few studies on slip coefficients on various faying surfaces in slip critical joints in comparison to both tension joints and bearing joints. The slip coefficient on a given joint geometry differs from the species of steel. The Table 1 of following section shows as to which factors are influencing on the slip coefficient.

\section{SLIP CRITICAL JOINT}

Besides the initial clamping force $T_{i}$, the slip coefficient $k_{s}$ as shown in Eq.(1) of the joint behavior up to the slip depends considerably on the treatments, and conditions of the faying surfaces. The bolt tension can be assumed to be equal in all bolts, and this reduces to $P_{\text {slip }}=k_{s} m n T_{i}$

where $P_{\text {slip }}$ describes the slip load of the tension plate , $m$ is the number of slip planes, and $n$ is the number of bolts in the joint.

Table 1. Slip coefficients based on the RCSC guideline

\begin{tabular}{clccc}
\hline \hline Type of steel & \multicolumn{1}{c}{ Treatment } & Average & $\begin{array}{c}\text { Standard } \\
\text { deviation }\end{array}$ \\
\hline A7, A36, A440 & Clean mill scale & 0.33 & 0.07 \\
& Red lead paint & 0.06 & - \\
A7, A36, Fe37 & Grit blasted, exposed (short period) & 0.53 & 0.06 \\
& Blast-cleaned zinc sprayed (t>2mils) & 0.40 & 0.04 \\
\hline
\end{tabular}

The American Institute of Steel Construction (AISC), and Eurocode3, regulate the proper slip coefficients that results from types of steel, and treatments of surfaces. Some criteria in the Research Council on Structural Connections (RCSC) and Eurocode3 are shown in Table 1, Table 2 respectively.

Table 2. Slip coefficient of Eurocode3

\begin{tabular}{|c|c|c|}
\hline Class & Slip factor & Surface Treatments \\
\hline A & 0.50 & $\begin{array}{l}\text { surfaces blasted with shot or grit, with any loose rust removed, no } \\
\text { pitting } \\
\text { surfaces blasted with shot or grit, and spray-metalized with } \\
\text { aluminum } \\
\text { surfaces blasted with shot or grit, and spray-metalized with a } \\
\text { zinc-based coating certified to provide a slip factor of not less than } \\
0.5\end{array}$ \\
\hline
\end{tabular}




\begin{tabular}{|c|c|l|}
\hline B & 0.40 & $\begin{array}{l}\text { I. surfaces blasted with shot or grit, and painted with an alkali-zinc } \\
\text { silicate paint to produce a coating thickness of } 50 \sim 80 \mathrm{~m}\end{array}$ \\
\hline C & 0.30 & $\begin{array}{l}\text { - surfaces cleaned by wire brushing of flame cleaning with any } \\
\text { loose rust removed }\end{array}$ \\
\hline D & 0.20 & - surfaces not treated \\
\hline
\end{tabular}

The slip coefficient depends on the faying surface treatments, and the hole sizes in the joint geometry. This study was planned in order to suggest a fundamental slip coefficient data for various surface conditions considering the domestic environment. In addition, the strain of each bolt with the specimens subjected to conditions of surfaces was measured for the long term relaxation of the initial clamping force.

\section{TEST PROGRAM}

A test was planned to determine the slip coefficient of faying surfaces under static tension loading and to determine the loss of clamping force. The main goal was to determine the shear capacity of the connections and to evaluate the relaxation of the clamping force under service loading. The material property of base plate was composed of SM490A and the thickness was $19 \mathrm{~mm}$. The thickness of the splice plate was $12 \mathrm{~mm}$. The steel plate, SM490A with a thickness range from $16 \mathrm{~mm}$ to $40 \mathrm{~mm}$, has the material property, that have $235 \mathrm{~N} / \mathrm{mm}^{2}$ of minimum yield strength, and from $400 \mathrm{~N} / \mathrm{mm}^{2}$ to $510 \mathrm{~N} / \mathrm{mm}^{2}$ of tensile strength. The candidates for high strength bolts were three kinds, that have 1,000 1,200 N/mm² of tensile strength, and at least $900 \mathrm{~N} / \mathrm{mm}^{2}$ of yield strength; torque shear bolts applied to KS B 2819 equivalent to ASTM F2289, torque shear bolts with zinc coating and ASTM A490 bolts. Each bolt was clamped by a calibrated wrench method. The specimen was designed not to reduce the slip load due to yielding base plate before the expected slip occurs. The test specimens had a double lap joint with two single holes as shown in Fig. 1. The pitch of bolt hole was $70 \mathrm{~mm}$ and the edge distance was $50 \mathrm{~mm}$.

\subsection{THE PREPARATION OF SPECIMENS}

There were five test parameters of faying surfaces: the clean mill, rust, red lead paint, zinc rich paint, and shot blast. The clean mill condition of faying surface was used in the same condition in which it was delivered to the laboratory. The rust condition of faying surface was used in the condition of one month outdoor exposure after controlling the shot blast.

The nominal thickness for coated treatment was planned as $120 \mu \mathrm{m}(4.7 \mathrm{mils})$. For comparison with the difference of coating thickness, at least another thickness of coating was added. Red lead paint was applied to the specimens to achieve a reddish brown color, and its average thickness was measured as $65 \mu \mathrm{m}$ (2.5mils) and $125 \mu \mathrm{m}(4.9 \mathrm{mils})$, respectively. Galvanizing paint was applied to specimens with a spraying zinc primer, and its average thickness was $128 \mu \mathrm{m}(5.0 \mathrm{mils}), 226 \mu \mathrm{m}(8.9 \mathrm{mils})$, respectively. The roughness of the shot blast on the surface ranged from $0.5 \mathrm{~mm}$ to $1.4 \mathrm{~mm}$. 


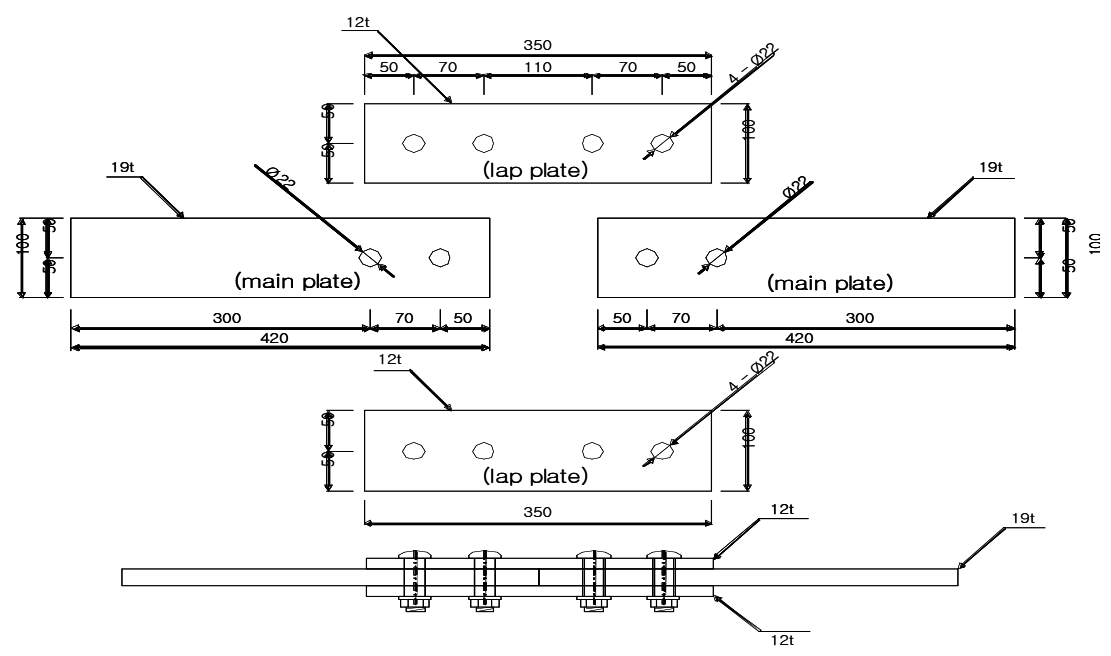

Fig. 1. Description of a double lap joint with two single holes

\subsection{TEST SETUP}

The test setup is shown in Fig. 2. The clamping force of high strength bolt on test was continued to reach the intended tension $178 \mathrm{kN}$, after torque of $15 \mathrm{kgm}$ at initial stage. The loading under tension was controlled by load until a slip occurred, and then, by displacement after major slip until a fracture of specimen occurred. For measuring the strain of bolt, the strain gages on the opposite side of the bolt shank were attached after drilling holes on the head of bolt as shown in Fig. 2

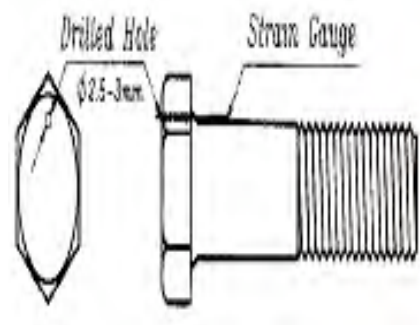

(a) drilling hole

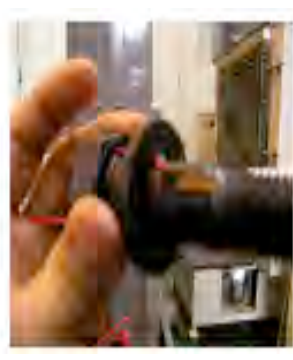

Fig. 2. Test setup

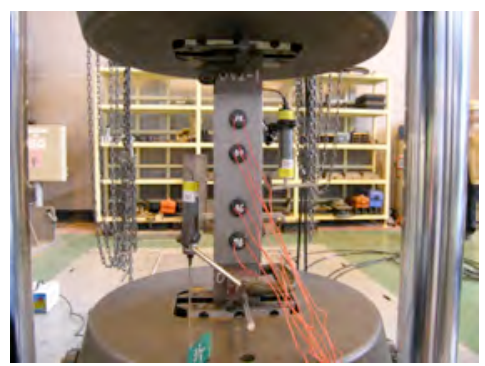

(b) Preparation of loading

Table 3. Description of Specimens

\begin{tabular}{|c|c|c|c|c|c|}
\hline $\begin{array}{l}\text { Specimen } \\
\text { I.D }\end{array}$ & Bolt Species* & $\begin{array}{l}\text { Treatm } \\
\text { Thickne }\end{array}$ & $\begin{array}{l}\text { ent of Surface } \\
\text { ss : [ } \mu \mathrm{m}(\text { mils })]\end{array}$ & Quantity & $\begin{array}{c}\text { Remark } \\
\text { (Bolt species*for } \\
\text { test) }\end{array}$ \\
\hline $2 \mathrm{KFM}$ & 1) KS B 2819 Torque & \multicolumn{2}{|c|}{ Clean mill } & 9 & 1), 2),3) \\
\hline 2KFP-1 & shear bolt (M20) & \multirow{5}{*}{$\begin{array}{c}\text { Red lead } \\
\text { paint } \\
\text { Zinc primer }\end{array}$} & $65(2.5)$ & 3 & 1) \\
\hline 2KFP-2 & 2) KS B 2819 Torque & & $125(4.9)$ & 6 & 2), 3) \\
\hline 2KFZ-1 & shear bolt with zinc & & $128(5.0)$ & 3 & 1) \\
\hline $2 \mathrm{KFZ}-2$ & coating (M20) & & $226(8.9)$ & 2 & 2) \\
\hline $2 \mathrm{KFR}$ & 3) ASTM A490 bolt & & Rust & 9 & 1), 2), 3) \\
\hline
\end{tabular}




\section{TEST RESULT}

The slip load on each treatment can be traced in the load-displacement curves in Fig. 4. The specimens of the clean mill scale on the surface (2KFM Series) exhibited that the slip coefficient was from 0.23 to 0.29 with a range from $167 \mathrm{kN}$ to $216 \mathrm{kN}$. This is in contrast to AISC specification for structural joints using ASTM A325 or A 490 Bolts (2000), which is suggested as 0.33 , whereas it is the similar to 0.33 with a standard deviation of 0.07 , as suggested by the RCSC guideline. The slip coefficient is also in the range of 0.20 to 0.35 reported by Architectural Institute of Japan(AIJ) guideline (2001). The difference between test results and American criteria firstly come from a difference between the clamping method of direct tension and the clamping method of torque control. Secondarily, the difference depends on how the clean mill scale on surfaces was treated.

For specimens of red lead paint on the surface (2KFP Series), in the case of paint thickness $65 \mu \mathrm{m}$, the average slip coefficient was 0.21 with a standard deviation of 0.02 while the slip load ranged from $139 \mathrm{kN}$ to $168 \mathrm{kN}$. This is coincided with the AIJ guideline. At the slip, the initial bolt clamping force diminished by $3 \%$ in Table 3 and Fig. 5. However, the slip coefficient of $125 \mu \mathrm{m}$ thick paint was dropped up to 0.09 with a standard deviation of 0.01 . This slip coefficient was the lowest value of the tested specimens. This result is similar to the Research Council on Structural Connections (RCSC) guideline which suggests a standard deviation of 0.06(Kulak, 2001). Primarily, the difference between test results and American criteria was due to thickness of coating. Secondarily the difference was derived from the working conditions, thickness, and formulation of the coating.

For specimens of zinc primer on the surface ( $2 \mathrm{KFZ}$ Series), the surface of the zinc thickness $128 \mu \mathrm{m}$ exhibited that the average slip coefficient was 0.42 with a standard deviation of 0.005 while the slip load ranged from $313 \mathrm{kN}$ to $326 \mathrm{kN}$. At the slip, the initial bolt clamping force loosened from $7 \%$ up to 12\%, as shown in Fig. 5. The surface of zinc thickness $226 \mu \mathrm{m}$ exhibited that the average slip coefficient was 0.45 with a standard deviation of 0.01 while the slip load ranged from $308 \mathrm{kN}$ to $330 \mathrm{kN}$. This was much higher than the range from 0.1 to 0.3 suggested by the AIJ guideline and the value, whereas it was the same as 0.40 with the standard deviation of 0.04 reported by RCSC design recommendations (Kulak, 2001). Unlike the red lead paint, the change of zinc primer thickness did not largely affect the slip coefficient. This behavior is believed to be due to the hardness of the metallic layer.

Table 4. Test results of slip coefficient

\begin{tabular}{c|c|c|c|c|c}
\hline \hline $\begin{array}{c}\text { Surface } \\
\text { Treatment }\end{array}$ & $\begin{array}{c}\text { Clamping } \\
\text { Force }(\mathrm{kN})\end{array}$ & $\begin{array}{c}\text { Slip load } \\
(\mathrm{kN})\end{array}$ & $\begin{array}{c}\text { Mean loss of } \\
\text { axial force on } \\
\text { bolt }(\%)\end{array}$ & $\begin{array}{c}\text { Mean Slip } \\
\text { Coefficient }\end{array}$ & $\begin{array}{c}\text { Standard } \\
\text { Deviation }\end{array}$ \\
\hline Mill scale & 178 & 170 & 2.5 & 0.27 & 0.01 \\
Red lead paint $(\mathrm{t}=65)$ & 178 & 151 & 3.0 & 0.21 & 0.02 \\
Red lead paint $(\mathrm{t}=125)$ & 178 & 58 & 1.5 & 0.09 & 0.01 \\
Zinc primer $(\mathrm{t}=128)$ & 178 & 319 & 9.8 & 0.42 & 0.005
\end{tabular}




\begin{tabular}{cccccc} 
Zinc primer $(\mathrm{t}=226)$ & 178 & 322 & 17.0 & 0.45 & 0.01 \\
Rust & 178 & 390 & 12.5 & 0.61 & 0.07 \\
Shot Blast & 178 & 420 & 9.2 & 0.50 & 0.08 \\
\hline
\end{tabular}

The specimens rusted on the surface (2KFR Series) exhibited that the average slip coefficient was 0.61 with a standard deviation of 0.07 . This value was barely included in the range from 0.45 to 0.7 suggested by the AIJ guideline. This test result is higher than values of the grit blasted and exposed condition for short period, 0.53 , reported by the RCSC guideline. While AISC spec regulates the slip coefficient as class B, 0.50 for rust condition, it is difficult to decide the quantitative state of rust. In the field, structural members are exposed at atmosphere for a period before erection. To simulate this field condition, the test for rust treatment condition was performed after the shot blasted plates had been exposed to an outdoor environment for a month at least. When a major slip occurred, the initial bolt clamping force dropped off from $10 \%$ to $16 \%$, as shown in Fig.5. In this case, the loss rate of the initial clamping force was the largest of the five treatments.

The specimens shot blasted on the surface (2KFB Series) exhibited that the average slip coefficient was 0.50 with a standard deviation of 0.08 . This value was included in the range between 0.4 and 0.7 suggested by the AIJ guideline. This value was a bit lower than the value of grit blasted treatment, 0.53 , which was reported by the RCSC guideline.

In case that the standard deviation both rust and blast treatment was much larger than the others. It is considered that the state of blast condition on surface was differed on the process of delivery, storage and test soon after the initial blast condition.

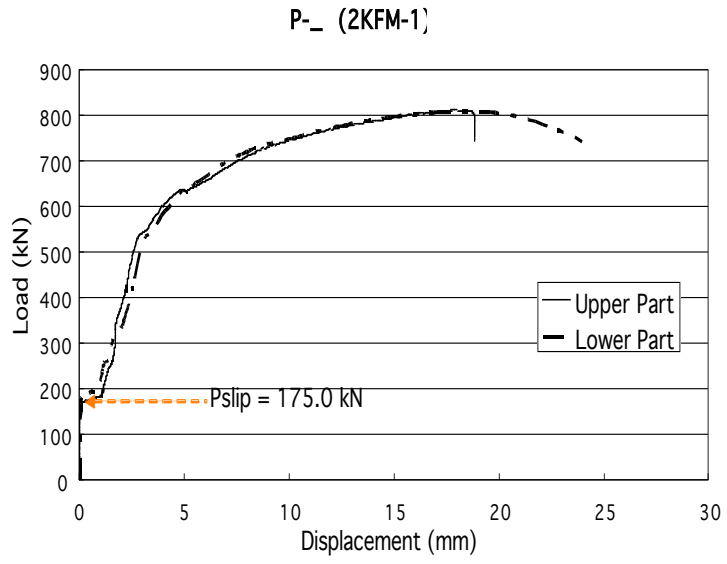

(a) Clean Mill

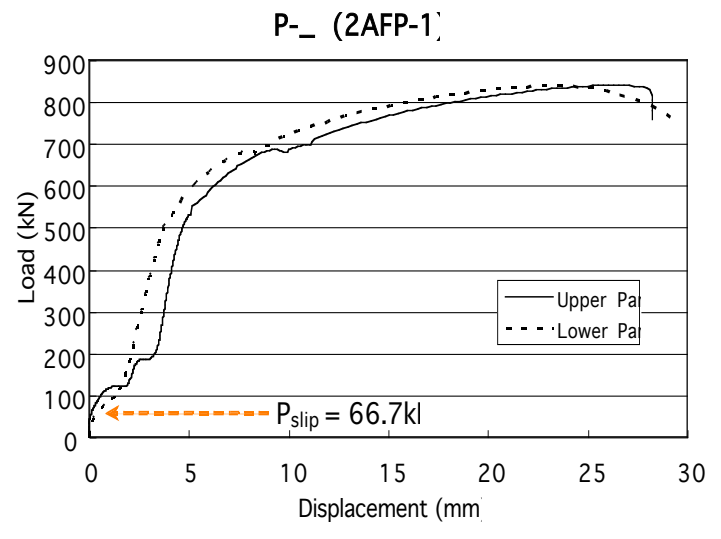

(b) Red lead paint $(t=125)$ 
P-_ (2KFZ-3)

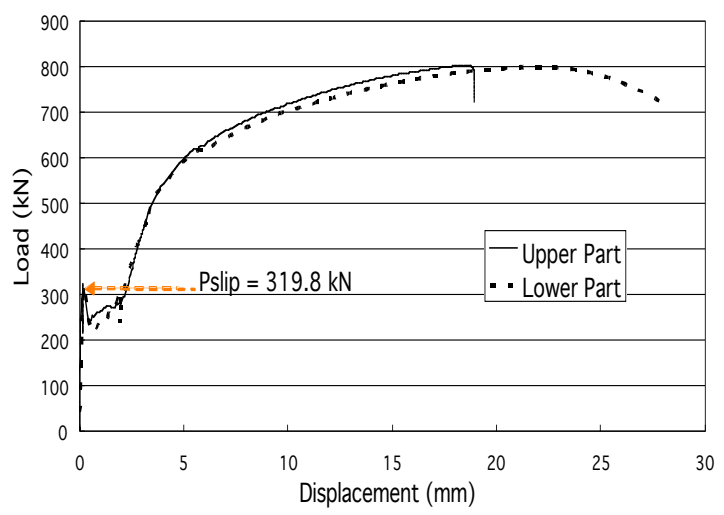

(c) Zinc Primer $(\mathrm{t}=128)$

P-_ (KFB-1)

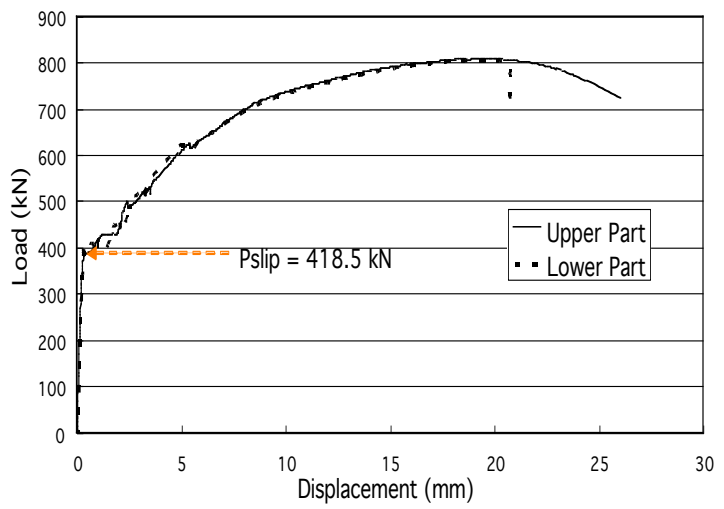

e) Shot blast
P-_ (2KFR-3)

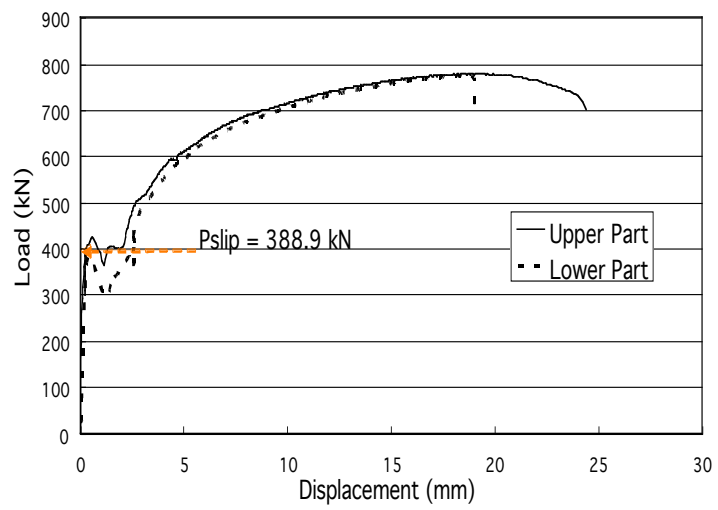

(d) Rust

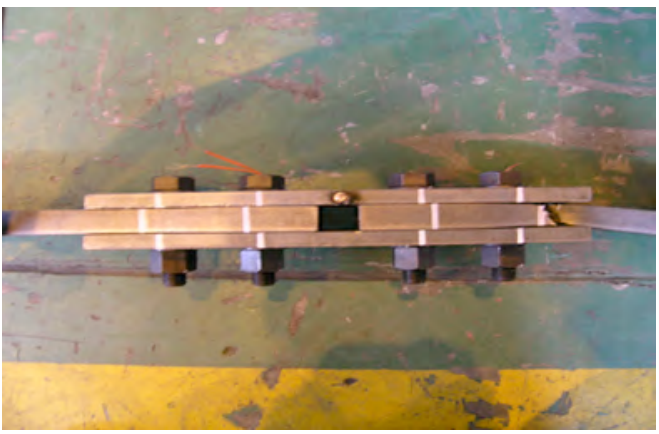

f) Failure mode

Fig. 4. Load-displacement curve on Faying Surface Treatment

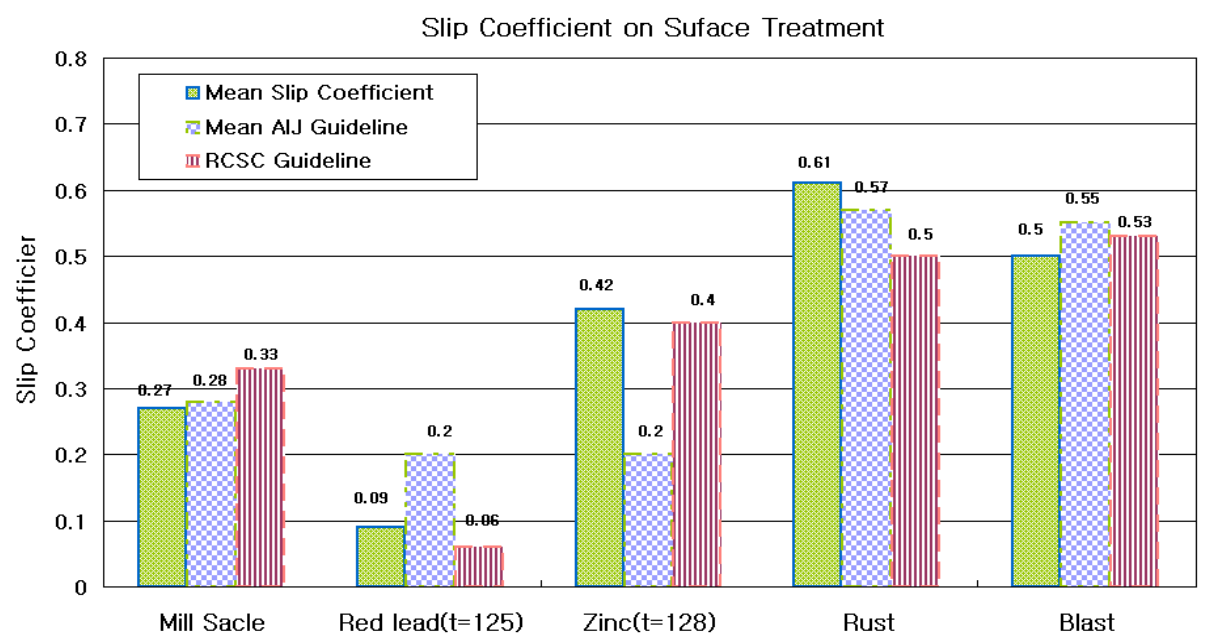

Fig. 5. Slip Coefficient on Faying Surface Treatment 
The followings are the synthetic results of slip coefficient test shown in Fig.6. Based on comparison with these tests in Fig.6, the followings were taken: in case of uncoated treatments of faying surfaces such as clean mill scale, rust and blasted scale, the tested value showed similar trends with RCSC and the AIJ guideline within the range of standard deviation, 0.05 . For comparison of material property, the type of steel used in this test, KS SM490A, is different from ASTM A36, one of the types of steel indicated in the RCSC guideline. The test result of the slip coefficient is reasonable for the calibrated wrench tightening method according to a standard deviation of $k_{s}$ (mean) taken as 0.07 for $k_{s} \leq 0.4$ and as 0.09 otherwise.(Kulak, 2001)

In the case of coated treatments as zinc primer and red lead primer, one among the three exhibited considerably different trends. It is surmised that the slip coefficient of the coated surface depends on the coating thickness. In this study, the coating thickness of red lead paint increased from $65 \mu \mathrm{m}$ to $125 \mu \mathrm{m}$, whereas the slip coefficient was lessened abruptly from 0.2 to 0.09 . Reduction in the bolt force up to $125 \mu \mathrm{m}$ has been shown to be as large as 7.3 times that for a bare blasted surface. However, the slip coefficient for zinc primer treatment showed a stable trend from 0.42 to 0.45 , regardless of increasing coating thickness from $128 \mu \mathrm{m}$ to $226 \mu \mathrm{m}$. This test result was in contrast to the general view, in which the coating thickness is an effective determinant for the slip coefficient. Even though the thickness coated on the surface is the same, the slip coefficient is also affected by the formulation of the coating manufacturer and the roughness of the faying surface.

As described in the introduction of this study, it is necessary to build a diverse slip coefficient applicable to Korean standard steel. From this test, the results can be used for the fundamental data to set up the slip coefficient for steel construction in the Republic of Korea. It is also recommended that the result of this test be used to establish the criteria of the slip coefficient for slip critical joints in steel structures of Korean Building Code.

According to Korean manufacturer's recommendation for coating for steel members, the coating thickness for red lead paint is suggested as $50 \mu \mathrm{m}$ and for zinc primer as $75 \mu \mathrm{m}$. For red lead paint, it is suggested that the minimum value of the mean slip coefficient $k_{s}$ is 0.2 under prior conditions of coating thickness $\leq 65 \mu \mathrm{m}$. For the zinc primer treatment, several tests of different thicknesses on the surface were additionally performed at $90 \mu \mathrm{m}, 180 \mu \mathrm{m}$, and $240 \mu \mathrm{m}$, and the values ranged from 0.40 to 0.46 . Therefore, the slip coefficient of zinc primer over thickness $90 \mu \mathrm{m}$ is considered as $k_{s} \geq 0.4$.

\section{CONCLUSION}

The tests were conducted on torque shear high strength bolted connections to determine how much the shear capacity is diminished by slip load and by relaxation in the clamping force for different surface treatments. The tests for slip coefficient consisted of five parameters on faying surfaces. In addition, the long term relaxation tests (1,000hours) have been performed. The following conclusions are made for this study.

From the slip coefficient test, uncoated surfaces, namely the rusted surface and shot blasted surface, exhibited slip coefficients of $0.61,0.50$ respectively, exceeding the required slip resistance. For red lead surface, the slip coefficient $k_{s}$ of 0.2 is considered appropriate under a prior condition of a coating thickness $\leq 65 \mu \mathrm{m}$. For zinc primer 
surfaces, it is considered that the slip coefficient of $k_{s}$ of 0.4 can be used for zinc primer over a thickness of $90 \mu \mathrm{m}$.

\section{REFERENCES}

ASTM F2280, 2006, "Twist off” type Tension Control Structural Bolt/Nut/Washer Assemblies, Steel, Heat Treated, 150ksi Minimum Tensile Strength, ASTM committee

Architectural Institute of Japan, 2003, Guidebook on Design and Fabrication of High Strength Bolted Connections, AIJ

Carl J. Lehmen, 2002, Direct Tension Indicators, Practical Periodical on Structural Design and Construction, May, 48-51

Geoffrey L. Kulak, John W. Fisher, John H.A. Struik, 2001, Guide to Design Criteria for Bolted and Riveted Joints, $2^{\text {nd }}$ Edition, AISC, Inc.

RCSC committee A.1, American Institute of Steel Construction, Inc, 2000, "Specification for Structural Joints Using ASTM A325 or A490 Bolts", Jun. AISC, Inc.

Jun Yang and John DeWolf , 2000, "Relaxation in High Strength Bolted Connections using Galvanized Steel”, J. of Bridge Engineering, May, 99-106.

Jun Yang and John DeWolf ,1999, "Mathematical Model for Relaxation in High Strength Bolted Connections", J. of Structural Engineering, Aug., 803-808

Geoffrey L. Kulak, Scott T. Undershutte ,1998, “Tension Control Bolts: Strength and Installation", J. of Bridge Engineering, Feb., 15-20

John H. Bickford, Sayed Nassar ,1998, Handbook of bolts and bolted joints, Marcel Dekker Inc., Madison Avenue, New York, NJ

Charles J. Oswald, Robert J. Dexter, and Steven K. Brauer,1996, "Field Study of Pretension in Large Diameter A490 Bolts", J. of Bridge Engineering, Aug. 121-126

Architectural Institute of Japan ,1993, Recommendations for the Design Fabrication of High Strength Bolted Joints, AIJ

John H. Bickford ,1990, An Introduction to the Design and Behavior of Bolted Joints, Marcel Dekker Inc., Madison Avenue, New York, NJ 